\title{
Pulp Diagnostic Tests
}

\section{Pulpa Tanı Testleri}

Aysun KARA TUNCER ${ }^{1}$, Müzeyyen KAYATAŞ², Safa TUNCER ${ }^{3}$

'Faculty of Endodontics, Bezmialem Vakif University, Faculty of Dentistry, Istanbul, Turkey

${ }^{2}$ Odontologist, Istanbul, Turkey

${ }^{3}$ Faculty of Dentistry, Istanbul University, Department of Restorative Dentistry, Istanbul, Turkey

\section{ABSTRACT}

Pulp diagnostic tests evaluate the neuropsychological status and blood flow of the pulp. These tests can be used in conjunction with other clinical tests, such as periodontal probing, percussion, palpation, mobility, and anesthesia, during diagnostic tests. In clinical practice, it is important to determine the pulp condition in deciding the correct treatment to be applied. The aim of this review is to provide information about the pulp diagnostic tests that are used in dental practice and to generalize the correct use of these tests.

\section{ÖZET}

Pulpa tanı testleri, pulpanın nörofizyolojik durumunun ve kan akımının değerlendirildiği testlerdir. $\mathrm{Bu}$ testler periodontal sondalama, perküsyon, palpasyon, mobilite ve anestezi testleri gibi diğer klinik testler ile birlikte teşhis aşamasında kullanılabilir. Klinik uygulamalarda pulpanın durumunun doğru tespit edilmesi uygulanacak doğru tedaviye karar verilmesinde büyük önem taşımaktadır. Bu derlemenin amacı diş hekimliği pratiğinde kullanılan pulpa tanı testleri hakkında bilgi vererek diş hekimleri tarafından doğru kullanımının yaygınlaştırılmasıdır.

Anahtar Sözcükler: Diş pulpası, diş pulpa testleri, diş

Key Words: Dental pulp, dental pulp tests, tooth

\section{Giriş}

Klinik uygulamalarda pulpanın durumun doğru tespit edilmesi büyük önem taşımaktadır. Pulpanın durumunun belirlenmesinde değişik teknikler kullanılmaktadır ve farklı klinik durumlarda hangi tekniğin kullanılmasının daha uygun olacağı ve güvenilir sonuç vereceğinin bilinmesi önemlidir. Bu makalenin amacı diş hekimliği pratiğinde kullanılan pulpa tanı testlerinin derlenmesidir.

Ehrmann (1) pulpa tanı testlerinin klinikte; operatif işlemlerden önce pulpanın durumu hakkında fikir vermesi nedeniyle, ağrı kaynağının bulunmasında ve radyolusent alanların teşhisinde önemli olduğunu bildirmiştir. Bunlara ilave olarak Mumford ve Bjorn (2) travma sonrasında, pulpa kuafajı ya da derin dolguların bulunduğu dişlerin incelenmesinde ve anestezi kontrolünde de pulpa tanı testlerinin kullanıldığını bildirmişlerdir.

Pulpa tanı testleri, hassasiyet testleri ve canlılık testleri olarak iki gruba ayrılmıştır. Pulpa hassasiyet testleri pulpanın nörofizyolojik durumunun değerlendirildiği testlerdir: termal testler, elektrik pulpa testi ve kavite testi. Pulpa canlılık testleri ise pulpanın kan akımının değerlendirildiği testlerdir: Lazer Doppler flowmetre, pulse oksimetre ve diş yüzey sıcaklığının ölçülmesi. Bu testler periodontal sondalama, perküsyon, palpasyon, mobilite ve anestezi testleri gibi diğer klinik testler ile birlikte teşhis aşamasında kullanılabilir $(3,4)$.

Hassasiyet kelimesinin sözlük anlamı uyaranlara yanıt verebilme özelliği olarak tanımlanmıştır. Termal testler ve elektrik pulpa testlerinde uyaranlara karşı pulpa sinir liflerinin yanıt verip vermediği değerlendirildiği için bu testler hassasiyet testleri olarak adlandırılır. Hassasiyet testleri sonucunda pulpanın canlı veya nekroz olduğuna karar verilir. Canlılık ise doku içinde kan akımı olduğunun bir göstergesidir. Literatürde gerçek canlılık testleri olarak Lazer Doppler flowmetre 
ve pulse oksimetre testleri bildirilmiştir. Bu yöntemler kolay uygulanabilir ve ekonomik olmaması nedeni ile diş hekimliğinde yaygın olarak kullanılmamaktadır $(5,6)$.

\section{Pulpanın Sinir Yapısı (İnnervasyonu)}

Pulpa hassasiyet testlerinin mekanizmalarını anlamak için pulpanın sinir yapısının özelliklerinin bilinmesi gerekmektedir. Pulpada iki tip sinir lifi bulunmaktadır: myelinli A lifleri ve myelinsiz $C$ lifleri. A lifleri çoğunlukla dentini innerve etmektedir ve çaplarına ve iletim hızlarına göre A beta ve A delta olarak ikiye ayrılırlar. A beta lifleri uyaranlara karşı A delta liflerinden daha hassastırlar ve çoğunlukla bir arada bulunmaktadırlar. A liflerinin \%90'ını A delta lifleri oluşturmaktadır. C lifleri pulpanın gövdesini innerve etmektedir. A delta liflerinini uyarılma eşiği $C$ liflerinden daha düşüktür ve $\mathrm{C}$ liflerini aktive edemeyen birçok uyarana karşı A delta lifleri hassastır (7). A delta lifleri akut, keskin ağrıları algılamaktadır ve dentin tübülleri içerisindeki frezle aşındırma ya da hava spreyi gibi hidromekanik uyaranlara karşı hassastır (8).

C lifleri donuk, küt, yanıcı ve lokalizasyonunun belirlenmesi güç olan ağrıları iletir ve pulpaya ulaşan uyaranlarla aktive olur $(9,10)$. C liflerinin ağrn eşiği oldukça yüksektir ve diş kuronun içinden ısındığında ya da soğuduğunda aktive olur. C lifleri bir kere aktive olduktan sonra yüzde ve çenelerde ağrıya neden olur. C lifleri doku yaralanmaları ile ilişkilidir ve iltihap mediyatörleri, damarlardaki kan miktarı, akım hızındaki değişiklikler, kan basıncının artması ile uyarılabilmektedir (11).

\section{Pulpa Hassasiyet Testleri}

\section{Termal Testler}

$\mathrm{Bu}$ testler pulpanın termal değişikliklere hassasiyetini ölçmek amacıyla dişe soğuk ve sıcak uyaranlar uygulanarak yapılmaktadır.

\section{Soğuk Testi}

En sık kullanılan pulpa hassasiyet testi soğuk testidir. Soğuk uygulanması dentin tübülleri içerisinde dentin sıvısının büzülmesine ve dentin tübüllerinin dışına doğru hareket etmesine neden olmaktadır $(12,13)$. Dentin sıvısının bu ani hareketi hidrodinamik kuvvetlerin pulpa dentin kompleksi içerisindeki A delta sinir lifleri üzerine etki ederek keskin lokalize ağrıya neden olur (14). Soğuk testi, buz çubukları $\left(0^{\circ} \mathrm{C}\right)$, karbodioksit gazı $\left(\mathrm{CO}_{2}\right)$ katı çubukları $\left(-78^{\circ} \mathrm{C}\right)$, etil klorit $\left(-5^{\circ}\right.$ C) ve diklorodiflorometan $(\mathrm{DDM})\left(-50^{\circ} \mathrm{C}\right)$ uygulanarak yapilır. Testler arasındaki temel fark uygulanan ısı farkıdır (15).

Soğuk test reversible ve irreversible pulpitisin ayırıcı tanısında kullanılabilir. Uyaran ortadan kaldırıldıktan sonra ağrının devam edip etmediği ve uyaran kaldırıldıktan sonra ağrının hemen ortadan kalkıp kalkmadığı değerlendirilmelidir. Etken ortadan kaldırıldıktan sonrada devam eden bir ağrı varsa bu irreversible pulpitisin belirtisi olabilir. Buna karşın etken ortadan kalktıktan sonra ağrı da ortadan kalkıyorsa bu durum reversible pulpitis tanısı olabilir. Reversible/irreversible pulpitis klinik bir teşhistir ve histolojik bulgularla uyum göster- fazla 15 saniye süre ile uygulanmalıdır. Uyaranın soğukluğu arttıkça dişin innervasyonu hakkında daha doğru bir değerlendirme sağlamaktadır (8). Soğuk testlerinin sıcak testlerinden daha güvenilir olduğu düşünülmektedir (17).

\section{Sicak Testi}

Sıcak testi ısıtılmış gutta percha kon ile ya da sıcak su ile yapılabilir. Gutta percha $65^{\circ} \mathrm{C}$ 'de yumuşamaktadır ve belli aletlerle $200^{\circ} \mathrm{C}^{\prime}$ ye kadar $1 s 1$ yükseltilebilmektedir. Ancak gutta percha çubukları yeterli ısıtılmadığında uyarı pulpayı etkilemeye ve bir cevap oluşturmaya yeterli olamamaktadır. Uygulanan ısısın süresi arttığında önce A delta lifleri uyarılır daha sonra C lifleri etkilenir (9). C liflerinin uyarılması ağrının uzun sürmesine neden olabilir bu nedenle isı testleri 5 saniyeden daha uzun sürmemelidir (16).

\section{Elektrik Pulpa Testi}

EPT'nin çalışma prensibi diş yüzeyine elektrik akımı uygulayarak pulpa dentin kompleksi içerisindeki intakt myelinli A delta delta liflerini uyarmaktır. Dentin kanalcıklarının içerisindeki dentin sıvısının iyonik akımı sonucunda intakt A delta liflerinden aksiyon potansiyeli oluşur ve pozitif sonuç elde edilir (18). Elektrik pulpa testi ile sinir iletimi ve sinir lifleri varlığı hakkında bilgi edinilir ama pulpanın bütünlüğü ve sağlık durumu belirlenemez. Elektrik pulpa testine alınan pozitif yanıtla pulpanın histolojik durumu arasında ilişki olmadığı bildirilmişsir (19). Travmaya uğramış dişler canlı olmalarına rağmen geçici olarak duyusal fonksiyonlarını kaybettikleri için elektrik pulpa testine yanıt vermezken parsiyel nekroz dişler pulpada kan akımı olmamasına rağmen pozitif yanit verirler (20).

Elektrik pulpa test cihazları pille çalışan hassas aletlerdir. Test yapılırken dişin izole edilmesi gereklidir. Mineyi kurutmak, interproksimal bölgelere plastik bir bant yerleştirmek ve rubber-dam kullanmak elektrik akımının komşu dişlere ve dişeti dokusuna ulaşmasını engeller (16).

Serbest sinir uçlarının uyarılmasına neden olan ve ağrıyı kaydedebilmek için gerekli olan en düşük uyarıya "ağrı eşiği” denir. Yeterli sayıda sinir ucu aktive edildiğinde ve total bir etki sağlandığında ağrı eşiği aşılır $(18,21)$. Test cihazının elektrotunun yerleştirileceği yer hakkında değişik görüssler bulunmaktadır. Sinir yoğunluğunun fazla olduğu yerde daha az elektrik akımı ile daha hızlı ve güçlü cevap oluşur (22). Dolayısıyla test cihazının elektrotu diş yüzeyinde pulpa boynuzuna yakın bir yere uygulanmalıdır. Bu bölge ön dişlerde 1/3 kesici kenar, arka dişlerde ise $2 / 3$ bölgesidir (16). Arka dişlerde test cihazının elektrotunun yerleştirileceği en doğru yer olarak meziyobukkal tüberkül tepesi gösterilmiştir (23).

\section{Pulpa Canlılık Testleri}

\section{Lazer Doppler Flowmetre}

LDF, mikro-vasküler sistemlerde ince kan damarlarında doğrudan kan akımı ölçümü yapabilen bir yöntemdir. İlk kez Gazelius ve ark. tarafından 1986 yılında kullanılmıştır. Diş hekimliğinde LDF, travmaya uğramış dişlerin canlılık 
kontrolünde pulpadaki kan akımının ölçülmesinde kullanılmaktadır. Peridontolojide kret augmentasyonundan sonra ve cerrahide Le Fort I osteotomiden sonra flapte gingival kan akımının ölçülmesinde de kullanılmaktadır $(24,25)$.

Bu teknik daha sonra pulpanın basınç değişiklikleri ve lokal anestezi sonrası kan akımındaki değişiklikleri monitorize etmek için kullanılmıştır.

Bu teknikte lazerin ürettiği infrared ışını kan akımı ölçülmek istenen doku üzerine yönlendirilmektedir. Işın dokunun içerisine girdiğinde dağılır ve hareket eden kırmızı kan hücreleri ve sabit doku elemanları tarafindan absorbe edilir. Doppler prensibine göre, fotonlar hareket eden kırmızı kan hücreleri ile karşılaştıklarında dağılıılar ve sıklıkla yer değiştirirler. Hareketsiz elemanlarla karşılaşan fotonlar dağılırlar ama Dopplerde yer değiştirmezler. Işının bir kısmı foton dedektörüne geri döner ve bir sinyal oluşur. Kırmızı kan hücreleri diş pulpasında hareket eden objelerin büyük kısmını oluşturmaktadır. Dolayısıyla geri yansıyan ve Doppler tarafindan toplanan ışın pulpadaki kan akımının ölçüsünü vermektedir $(26,27)$.

\section{Pulse Oksimetre}

PO, tıpta intravenöz anestezi uygulanan hastalarda kanda oksijen satürasyon $\left(\mathrm{SaO}_{2}\right)$ seviyelerinin kaydedilmesi için yaygın olarak kullanılan $\mathrm{SaO}_{2}$ görüntüleme aletidir. Pulse oksimetre, tamamen objektif bir testtir ve hastadan alınan subjektif tepkilere dayanmamaktadır. Pulse oksimetre sensörünün iki tane ışık yayan ucu vardır. Biri kırmızı ışı $(640 \mathrm{~nm})$ iletir, diğeri infrared $(940 \mathrm{~nm})$ ışık iletir. Bu uçların uygulandığı dokunun diğer tarafında ise bir fotodedektör bulunmaktadır. Oksijenli hemoglobin ve oksijen içermeyen hemoglobin farklı miktarlarda kırmızı ve kızılötesi ş̧ık absorbe ederler. Bu da fotodedektöre yansır. Kırmızı ışık absorbsiyonundaki pulsatil değişiklik ile kızıl ötesi ışık absorbsiyonundaki pulsatil değişiklik arasındaki ilişki pulse oksimetre tarafından değerlendirilir ve arteryel kandaki satürasyon saptanır (16).

Gopikrishna ve ark. insan dişlerinde pulpa canlılı̆̆ının saptanması için bir pulse oksimetre sistemi geliştirmişlerdir. Pulse oksimetre dental probu ile termal ve elektrikli pulpa testlerinin güvenilirliğini karşılaşıırmışlar ve pulpası canlı dişlerde soğuk testi ile $\% 81$, elektrikli pulpa testi ile $\% 74$ ve pulse oksimetre ile \%100 doğru sonuç elde edilmiştir. Nekrotik pulpalı dişlere soğuk testi ile $\% 92$, elektrikli pulpa testi ile $\% 91$ ve pulse oksimetre ile \%95 doğru sonuç elde edilmiştir $(28,29)$.

Pulse oksimetenin doğru sonuç verebilmesi için arteriyel kan basıncının normal olması gerekmektedir. Arterlerden kan akımı az olduğunda pulse oksimetrenin ölçüm yapabilmesi güç olmaktadır. Kuronal pulpada kalsifik değişiklikler olduğunda da pulse oksimetrenin, daha az hassasiyet gösterdiği bildirilmiştir. Bu durum travma, derin restorasyonların bulunduğu dişler ve fizyolojik yaşlanma ile gelişmektedir. Bu vakalarda kuronal kalsifikasyonu olan canlı dişlerde hatalı negatif cevap alınabilir (16).

\section{Sonuç}

Klinik uygulamalarda pulpanın durumunun doğru tespit edilmesi büyük önem taşımaktadır. Her ne kadar hassasiyet testleri klinisyenlerin büyük bölümü tarafından uygulanıyor olsa da bir takım kısıtlamaları bulunmaktadır. Pulpadaki kan akımının ölçülmesi ile ilgili çalışmalar yapıldıkça ve bu konu geliştirildikçe pulpanın durumunun belirlenmesinde daha objektif, doğru ve kesin sonuçlar elde edilecektir.

Peer-review: Externally peer-reviewed.

Author Contributions: Concept - M.K., Design - A.K.T.; Supervision A.K.T.; Funding - S.T.; Literature Review - S.T.; Writing - A.K.T.; Critical Review - S.T., M.K.

Conflict of Interest: No conflict of interest was declared by the authors.

Financial Disclosure: The authors declared that this study has received no financial support.

Hakem Değerlendirmesi: Dış bağımsız.

Yazar Katkıları: Fikir - M.K.; Tasarım - A.K.T.; Denetleme - A.K.T.; Kaynaklar - S.T.; Literatür Taraması - S.T.; Yazıyı Yazan - A.K.T.; Eleștirel İnceleme - S.T., M.K.

Çıkar Çatışması: Yazarlar çıkar çatışması bildirmemişlerdir.

Finansal Destek: Yazarlar bu çalışma için finansal destek almadıklarını beyan etmişlerdir.

\section{Kaynaklar}

1. Ehrmann EH. Pulp testers and pulp testing with particular reference to the use of dry ice. Aust Dent J, 1977; 22: 272-9. [CrossRef]

2. Mumford JM, Bjorn H. Problems in electric pulp testing and dental algesimetry. Int Dent J 1962/1976; 12: 161-79.

3. Jafarzadeh H, Abbott PV. Review of pulp sensibility tests. Part I: general information and thermal tests. Int Endod J 2010; 43: 738-62. [CrossRef]

4. Abd-Elmeguid A, Yu DC. Dental pulp neurophysiology: part 2. Current diagnostic tests to assess pulp vitality. J Can Dent Assoc. 2009; 75: 139-43.

5. Jafarzadeh H. Laser Doppler flowmetry in endodontics:a review. Int Endod J 2009; 42: 476-90. [CrossRef]

6. Jafarzadeh H, Rosenberg PA. Pulse oximetry: review of a potential aid in endodontic diagnosis. J Endod 2009; 35: 329-33. [CrossRef]

7. Olgart L. Excitation of intradental sensory units by pharmacological agents. Acta Physiol Scand 1974; 92: 48-55. [CrossRef]

8. Byers MR. Dental sensory receptors. Int Rev Neurobiol 1984; 25 : 39-94. [CrossRef]

9. Narhi MVO. The characteristics of intradental sensory units and their responses to stimulation. J Dent Res 1985; 64: 564-71.

10. Markowitz K, Kim S. Hypersensitive teeth. Experimental studies of dentinal desensitizing agents. Dent Clin North Am 1990; 34: 491-501.

11. Narhi MVO. The neurophysiology of the teeth. Dent Clin North Am 1990; 34: 439-48.

12. Brännström M. A hydrodynamic mechanism in the transmission of pain-producing stimuli in dentine. In: Anderson DJ (ed.). Sensory Mechanisms in Dentine.Oxford: Pergamon Press, 1963: 73-7.

13. Brännström $M$. The hydrodynamic theory of dentinal pain: sensation in preparations, caries and dentinal crack syndrome. J Endod 1986; 12: 453-7. [CrossRef] 
14. Ingle JI, Bakland LK Endodontics, 5th edn. London: 2002 BC Decker Inc.

15. Fleury A, Regan JD. Endodontic diagnosis: clinical aspects. J Ir Dent Assoc 2006; 52:28-38.

16. Gopikrishna V, Pradeep G, Venkateshbabu N. Assessment of pulp vitality: a review. Int J Paediatr Dent. 2009; 19: 3-15. [CrossRef]

17. Seltzer S, Bender IB, Ziontz M. The dynamics of pulpal inflammation: correlation between diagnostic data and actual histological findings in the pulp. Oral Surg Oral Med Oral Pathol 1963; 16: 973-7. [CrossRef]

18. Narhi M, Virtanen A, Kuhta J, Huopaniemi T. Electrical stimulation of teeth with a pulp tester in the cat. Scand J Dent Res 1979; 87: 32-8.

19. Mumford JM. Pain perception threshold on stimulating human teeth and the histological condition of the pulp. British Dental Journal 1967; 123, 427-33.

20. Petersson K, Soderstrom C, Kiani-Anaraki M, Levy G. Evaluation of the ability of thermal and electrical tests to register pulp vitality. Endod Dent Traumatol 1999; 15: 127-31. [CrossRef]

21. Johnsen DC. Innervation of teeth: qualitative, quantitative, and developmental assessment. J Dent Res 1985; 64: 555-63.

22. Bender IB, Landau MA, Fonsecca S, Trowbridge HO. The optimum placement-site of the electrode in electric pulp testing of the 12 anterior teeth. J Am Dent Assoc 1989; 118: 305-10. [CrossRef]
23. Lin J, Chandler NP, Purton D, Monteith B. Appropriate electrode placement site for electric pulp testing first molar teeth. J Endod 2007; 33: 1296-8. [CrossRef]

24. Zanetta-Barbosa D, Klinge B, Svensson H. Laser Doppler flowmetry of blood perfusion in mucoperiosteal flaps covering membranes in bone augmentation and implant procedures. A pilot study in dogs. Clin Oral Implants Res 1993; 4:35-8. [CrossRef]

25. Dodson TB, Neuenschwander MC, Bays RA. Intraoperative assessment of maxillary perfusion during Le Fort I osteotomy. J Oral Maxillofac Surg 1994; 52: 827-31. [CrossRef]

26. Gazelius B, Olgart L, Edwall B, Edwall L. Non invasive recording of blood flow in human dental pulp. Endod Dent Traumatol 1986; 2: 219-21. [CrossRef]

27. Wilder Robinson-Smith PEEB. A new method for the non invasive measurement of pulpal blood. Int Endod J 1988; 21: 307-12. [CrossRef]

28. Gopikrishna V, Kandaswamy D, Tinagupta K. Assessment of the efficacy of an indigenously developed pulse oximeter dental sensor holder for pulp vitality testing - an in vivo study. Indian J Dent Res 2006; 17: 111-3. [CrossRef]

29. Gopikrishna V, Kandaswamy D, Tinagupta K. Comparison of electrical, thermal and pulse oximetry methods for assessing pulp vitality in recently traumatized teeth. J Endod 2007; 33: 531-5. [CrossRef] 